\title{
Autophagy promotes paclitaxel resistance of cervical cancer cells: involvement of Warburg effect activated hypoxia-induced factor $1-\alpha$-mediated signaling
}

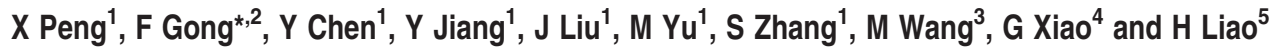

Paclitaxel is one of the most effective chemotherapy drugs for advanced cervical cancer. However, acquired resistance of paclitaxel represents a major barrier to successful anticancer treatment. In this study, paclitaxel-resistant HeLa sublines (HeLa-R cell lines) were established by continuous exposure and increased autophagy level was observed in HeLa-R cells. 3-Methyladenine or ATG7 siRNA, autophagy inhibitors, could restore sensitivity of HeLa-R cells to paclitaxel compared with parental HeLa cells. To determine the underlying molecular mechanism, differentially expressed proteins between HeLa and HeLa-R cells were identified by two-dimensional gel electrophoresis coupled with electrospray ionization quadrupole time-offlight MS/MS. We found glycolysis-associated proteins were upregulated in HeLa-R cell lines. Inhibition of glycolysis by 2-deoxy$\mathrm{D}$-glucose or koningic acid could decrease autophagy and enhance sensitivity of HeLa-R cells to paclitaxel. Moreover, glycolysis could activate HIF1- $\alpha$. Downregulation of HIF1- $\alpha$ by specific siRNA could decrease autophagy and resensitize HeLa-R cells to paclitaxel. Taken together, a possible Warburg effect activated HIF1- $\alpha$-mediated signaling-induced autophagic pathway is proposed, which may provide new insight into paclitaxel chemoresistance.

Cell Death and Disease (2014) 5, e1367; doi:10.1038/cddis.2014.297; published online 14 August 2014

Cervical cancer, a common malignant tumor, is an vital cause of morbidity and mortality among women worldwide. ${ }^{1}$ Paclitaxel, the targets of which are the microtubules of cancer cells, is one of the most useful anticancer drugs against cervical cancer. ${ }^{2}$ Paclitaxel can destroy the dynamic equilibrium of tubulin between soluble dimers and polymerized form to make the microtubule structure stable. In addition, it is a strong inhibitor of chromosomal replication by obstructing tumor cells in the mitotic phases or late $\mathrm{G} 2 .^{3}$ However, acquired chemoresistance to paclitaxel obviously limits the successful treatment of cervical cancer. One main explanation on tumor cell resistance to paclitaxel is the overexpression of $\mathrm{P}$-glycoprotein (P-gp, MDR-1), which works as a drug efflux pump. However, clinical utility of P-gp inhibitors are often ineffective or toxic at the doses required to attenuate P-gp function. ${ }^{4-6}$ Other possible mechanisms of action contain alterations in the drug-binding affinity of the microtubules, ${ }^{7}$ changes of tubulin structure and cell cycle deregulation. ${ }^{8-11}$ Thus, paclitaxelresistant mechanisms are complicated and still not entirely clear until now.

As a self-proteolysis procedure in almost all eukaryotic cells, autophagy activated by adverse cellular environment contributes to the breakdown of intracellular components within lysosomes to supply an alternative source of energy and thus sustain cell survival. ${ }^{12,13}$ However, it has been shown that cell death could be inhibited by suppressing expression of some vital autophagy-associated genes, underscoring the functional role of autophagy in the cell death. ${ }^{14,15}$ Several important autophagy-associated proteins, such as Beclin 1 and Ptdlns3K class I, have important roles in the control of both autophagy and apoptosis. ${ }^{16-18}$ Thus, the function of autophagy has been described as a double-edged sword that can work both as a protector and killer of cells, which depends on the developmental stage of the disease or the surrounding microenvironment. ${ }^{19}$

It has been reported that anticancer treatment (such as radiotherapy, chemotherapy and molecular targeted therapy) could induce autophagy in cancer cells. In addition, impaired autophagy could make cancer cells sensitize to these therapies, indicating a hopeful strategy to better the efficacy of cancer treatment. ${ }^{11,20-22}$ However, few studies on the underlying molecular mechanism of chemoresistance-associated autophagy were carried out.

In this study, increased levels of autophagy were observed in paclitaxel-resistant HeLa sublines (HeLa-R cell lines). 3-Methyladenine (3-MA) or ATG7 siRNA, autophagy inhibitors, restored sensitivity of HeLa-R cells to paclitaxel. In addition, a group of metabolic proteins with significant alteration were

\footnotetext{
${ }^{1}$ Department of Medical Oncology, Cancer Center, State Key Laboratory of Biotherapy, West China Hospital, Sichuan University, Chengdu 610041, People's Republic of China; ${ }^{2}$ Department of Gynecology and Obstetrics, Second West China Hospital; and State Key Laboratory of Biotherapy and Cancer Center, West China Hospital, Sichuan University, Chengdu 610041, People's Republic of China; ${ }^{3}$ Center of Infectious Diseases, West China Hospital, Sichuan University, Chengdu 610041, People's Republic of China; ${ }^{4}$ Department of Pathology, Zunyi Medical College, Zunyi 563003, People's Republic of China and ${ }^{5}$ Department of Pathology, Wenzhou Central Hospital, Wenzhou 325000, People's Republic of China

${ }^{*}$ Corresponding author: F Gong, Department of Gynecology and Obstetrics, Second West China Hospital; and State Key Laboratory of Biotherapy and Cancer Center, West China Hospital, Sichuan University, Chengdu 610041, People's Republic of China. Tel: +86 28 85164059; Fax: +86 28 85164060; E-mail: pxx2014@ sohu.com Abbreviations: HeLa-R, paclitaxel-resistant HeLa sublines; IC50, inhibitory concentration 50; TEM, transmission electron microscopy; 2-DE, two-dimensional gel electrophoresis; ESI-Q-TOF, electrospray ionization quadrupole time-of-flight; 2-DG, 2-deoxy-D-glucose; KA, koningic acid

Received 01.1.14; revised 06.5.14; accepted 27.5.14; Edited by GM Fimia
} 
identified by proteomics, which may suggest the switch of cellular metabolism from tricarboxylic acid cycle to glycolysis. Moreover, inhibition of glycolysis by 2-deoxy-D-glucose (2-DG) or koningic acid (KA) could inhibit autophagy and enhance sensitivity of HeLa-R cells to paclitaxel. In addition, HIF $1-\alpha$ could be activated by glycolysis and HIF1- $\alpha$ siRNA could decrease autophagy and resensitize HeLa-R cells to paclitaxel. In conclusion, a possible Warburg effect activated HIF1- $\alpha$-mediated signaling-induced autophagic pathway is proposed, which may provide new insight into paclitaxel chemoresistance.

\section{Results}

Characterization of paclitaxel-resistant HeLa-R cells. MTT and neutral red uptake assay were performed to confirm resistance to paclitaxel. The inhibitory concentration 50 (IC50) value for HeLa parental cells was as low as $1.87 \mathrm{nM}$ paclitaxel. However, the IC50 value $(29.06 \mathrm{nM})$ of HeLa-R cells for paclitaxel was far higher than in HeLa cells, indicating approximately 16-fold greater resistance. Examples of the concentration-response curves are shown in Figures $1 \mathrm{~A}$ and $\mathrm{B}$. Clonogenic assay showed $2 \mathrm{nM}$ paclitaxel obviously inhibited cell proliferation in HeLa parental cells (Figure 1C), while no statistically significant differences were found in the number of HeLa-R cells after treatment with $2 \mathrm{nM}$ paclitaxel (Figure 1D).

The quantitative analysis of sub-G1 cells by flow cytometry was carried out to estimate the number of apoptotic cells. HeLa parental cells treated with $2 \mathrm{nM}$ paclitaxel for $48 \mathrm{~h}$ had an obvious sub-G1 peak compared with the untreated group. However, HeLa-R cells treated with $2 \mathrm{nM}$ paclitaxel did not have a conspicuous sub-G1 peak (Figure 1E).

In order to study the role of P-gp in paclitaxel resistance of HeLa-R cells, the expression of P-gp was examined by western blot. No difference in protein expression level was observed between HeLa and HeLa-R cells (data not shown). Moreover, inhibition of P-gp by verapamil (verap) could not restore HeLa-R cells sensitivity to paclitaxel (Figure 1F). Thus, in this study $\mathrm{P}$-gp did not have an important role in paclitaxel resistance of HeLa-R cells.

Autophagy was activated in HeLa-R cells. Transmission electron microscopy (TEM) was used to analyze ultrastructure of HeLa and HeLa-R cells. Increased autophagosomes were found in the cytoplasm of HeLa-R cells, while autophagosomes could rarely be observed in HeLa parental cells (Figure 2a). LC3 immunofluorescence was conducted to assess if recruitment of LC3-II to autophagosomes in HeLa-R cells. Punctate patterns of LC3 immunofluorescence

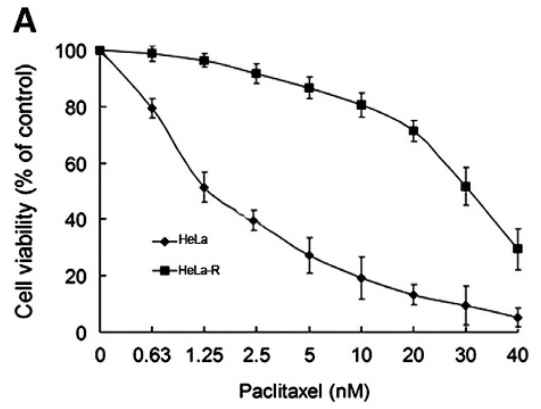

D

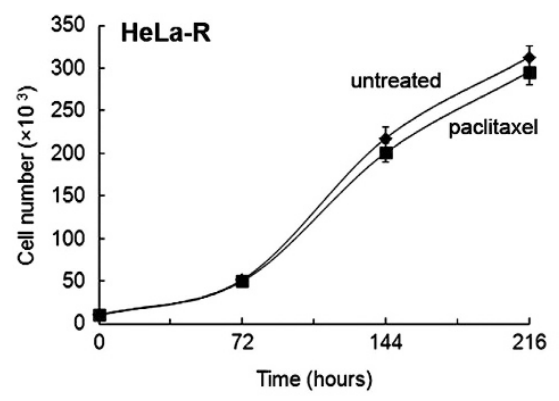

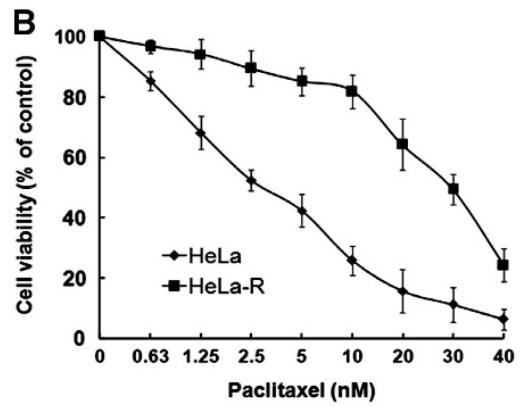

E

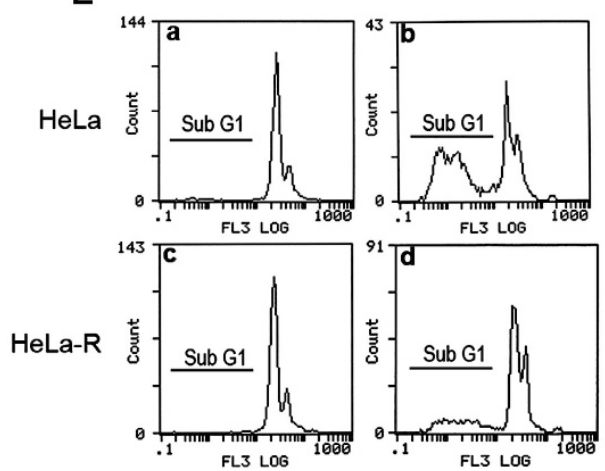

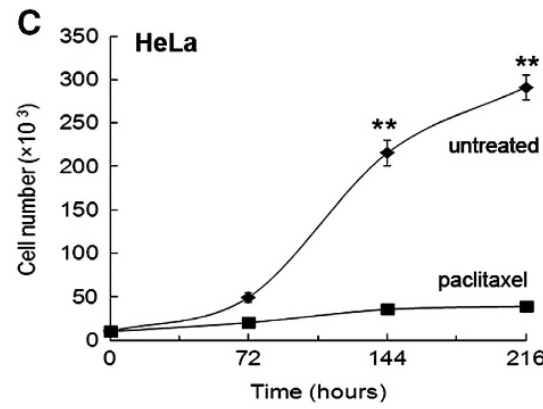

$\mathbf{F}$

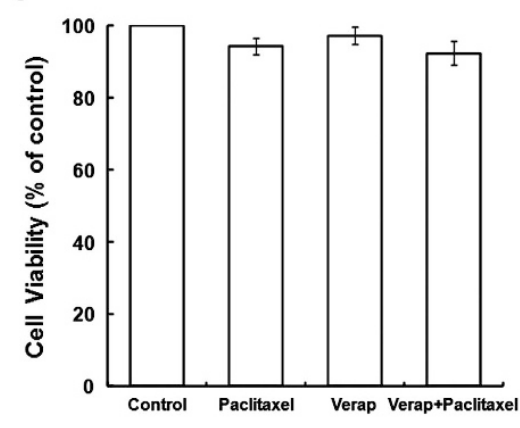

Figure 1 Characterization of paclitaxel-resistant HeLa-R cells. (A and B) MTT and neutral red uptake assay were performed to evaluate cytotoxicity of paclitaxel to HeLa and paclitaxel-resistant HeLa-R cells under treatment with indicated concentrations of paclitaxel. The IC50 value of HeLa-R cells for paclitaxel was far higher than in HeLa cells, indicating approximately 16 -fold greater resistance. ( $C$ and $\mathbf{D}$ ) HeLa parental cells and paclitaxel-resistant HeLa-R cells were plated in 24-well plates at a density of 10000 cells per well and cultured with regular medium in the absence or presence of $2 \mathrm{nM}$ paclitaxel. The data presented are from three independent experiments made in duplicate obtained after $0,3,6$ and 9 days. No statistically significant differences were observed in the number of HeLa-R cells growing in the presence of $2 \mathrm{nM}$ paclitaxel up to 9 days whereas $2 \mathrm{nM}$ paclitaxel significantly reduced cell proliferation in HeLa parental cells. Slope of the growth curves clearly denotes a faster proliferation of HeLa-R cells regardless paclitaxel exposure. (E) HeLa and HeLa-R cells were treated with paclitaxel for $48 \mathrm{~h}$. (a) Untreated HeLa cells; (b) paclitaxel-treated HeLa cells; (c) untreated HeLa-R cells; (d) paclitaxel-treated HeLa-R cells, with (a) $3.6 \%$, (b) $51.3 \%$, (c) $4.1 \%$, (d) $10.9 \%$ sub-G1 cells (apoptotic cells), respectively, as assessed by flow cytometry. (F) Inhibition of P-gp by verap could not restore HeLa-R cells sensitivity to paclitaxel. ${ }^{* \star} P<0.01$ 
a
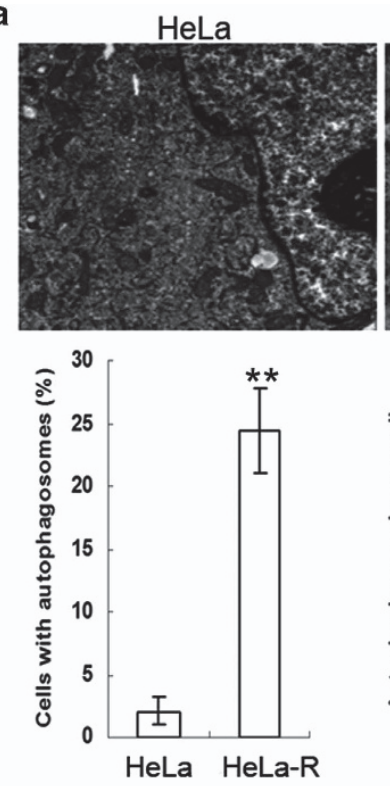

b

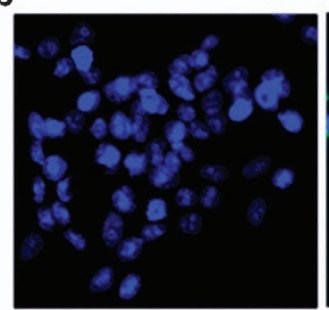

HeLa
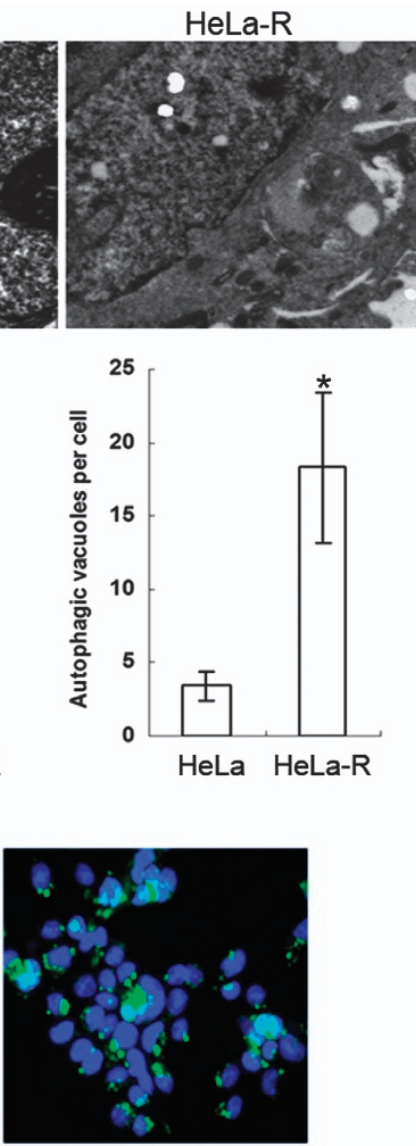

HeLa-R
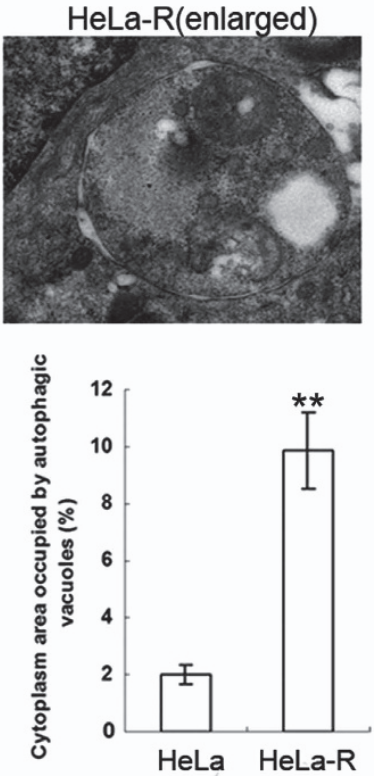

C HeLa HeLa-R

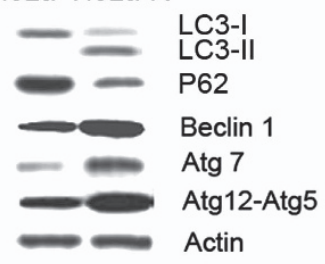

Figure 2 Autophagy was activated in HeLa-R cells. (a) Representative transmission electron micrographs depicting ultrastructures of HeLa and HeLa-R cells. (b) LC3 immunofluorescence of HeLa and HeLa-R cells. Punctate patterns of LC3 immunofluorescence were observed in HeLa-R cells by a fluorescence microscope, whereas it could not be seen in HeLa parental cells. (c) Western blot of LC3-I/II, P62, Beclin 1, Atg7 and Atg12-Atg5 conjugate using lysates from HeLa and HeLa-R cells. $\beta$-Actin was used as an equal loading control. ${ }^{\star} P<0.05 ;{ }^{* *} P<0.01$

were observed in HeLa-R cells by a fluorescence microscope, whereas it could not be seen in HeLa parental cells (Figure 2b).

LC3-I protein ( $18 \mathrm{kDa}$ ) can be cleaved by autophagic stimuli to LC3-II (16 kDa), which is localized in autophagosome. As shown in Figure 2c, LC3-II protein was detectable in HeLa-R cells, whereas the expression of LC3-II was undetectable in HeLa parental cells. Furthermore, western blot analysis indicated that P62 (also called SQSTM1, it is degraded when autophagy is induced and may be used as a marker to study autophagic flux) was downregulated, while Beclin 1, Atg7 and Atg12-Atg5 conjugate were upregulated in HeLa-R cells compared with HeLa parental cells (Figure 2c). These data showed that autophagy was activated in HeLa-R cells.

Inhibition of autophagy restored HeLa-R cells sensitivity to paclitaxel. In order to study whether autophagy results in chemoresistance of HeLa-R cells, we treated HeLa-R cells with 3-MA (a widely used autophagy inhibitor, specific inhibitor of PI3K) to inhibit autophagy, then assessed the cells sensitivity to paclitaxel. Both data from electron microscopy and LC3 immunofluorescence showed that 3-MA ( $5 \mathrm{mM})$ effectively inhibited autophagy activation of
HeLa-R cells (Figure 3A). Corresponding to decreased autophagosome, apoptosis was markedly enhanced in 3-MA plus paclitaxel-treated group, compared with treatment with paclitaxel alone $(2 \mathrm{nM}), 3-\mathrm{MA}$ alone $(5 \mathrm{mM})$ and PBS control (Figure 3B). Cell viability and number of HeLa-R cells were also significantly reduced in 3-MA plus paclitaxeltreated group compared with treatment with paclitaxel alone (2 nM), 3-MA alone (5 mM) and PBS control (Figures $3 \mathrm{C}$ and D).

In order to further confirm inhibition of autophagy could restore HeLa-R cells sensitivity to paclitaxel, we used ATG7 siRNA to inhibit autophagy. ATG7 silencing by siRNA can inhibit the generation of autophagosomes, and thus prevent the induction of autophagy. ${ }^{23}$ As shown in Figures 3E and $F$, cell viability and number of HeLa-R cells were also significantly reduced in ATG7 siRNA plus paclitaxel-treated group compared with the controls.

In addition, parental HeLa cells were tested for response to 3-MA and ATG7 siRNA. As shown in Figures 3G and $\mathrm{H}$, cell viability and number of HeLa cells were not significantly reduced in 3-MA plus paclitaxel-treated group compared with treatment with paclitaxel alone. Furthermore, ATG7 siRNA could not increase paclitaxel sensitivity in parental HeLa cells (Figures $3 \mathrm{I}$ and $\mathrm{J}$ ). In conclusion, our data suggested 


\section{A}
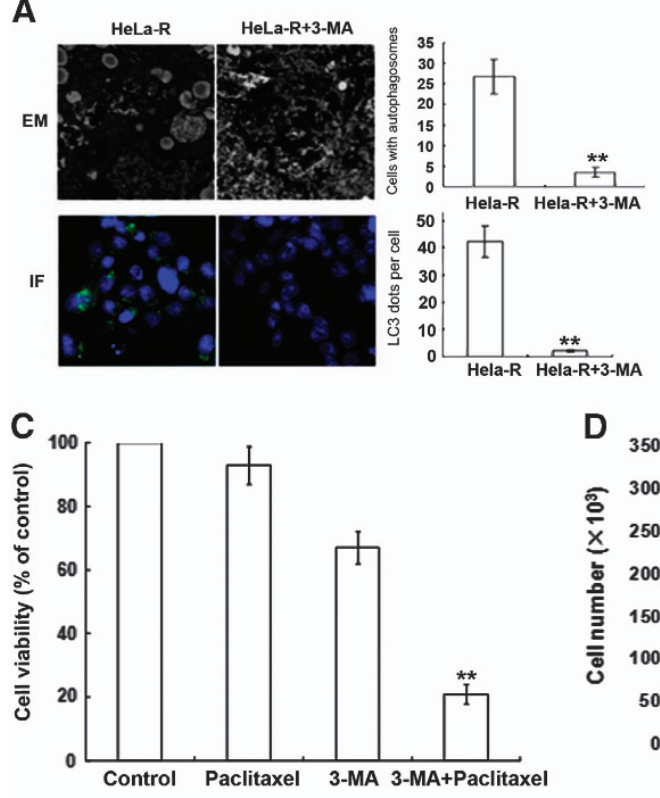

E

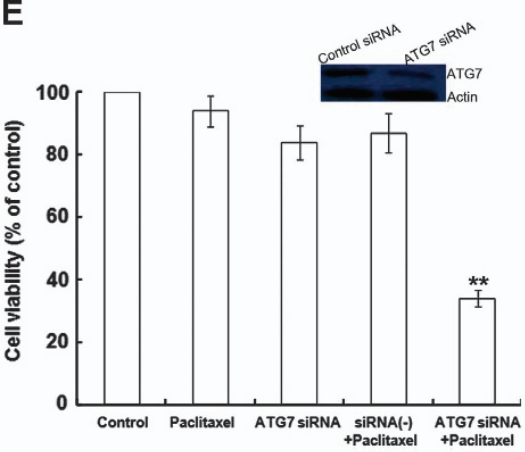

G
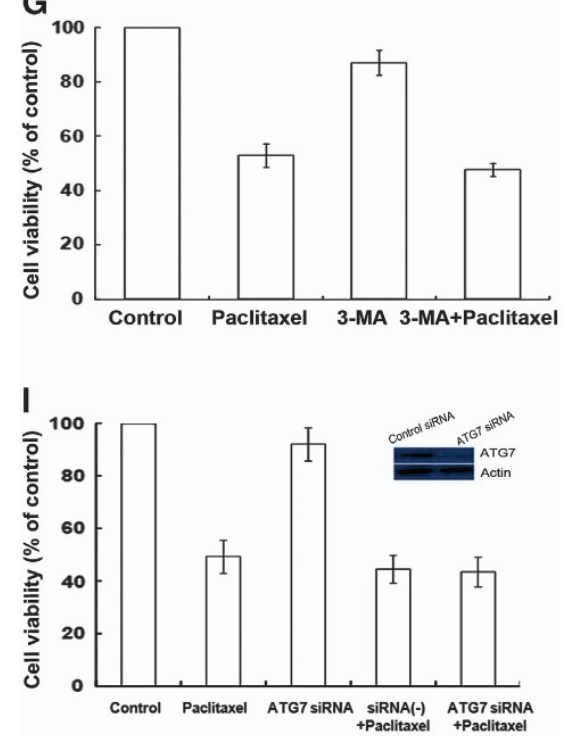

B
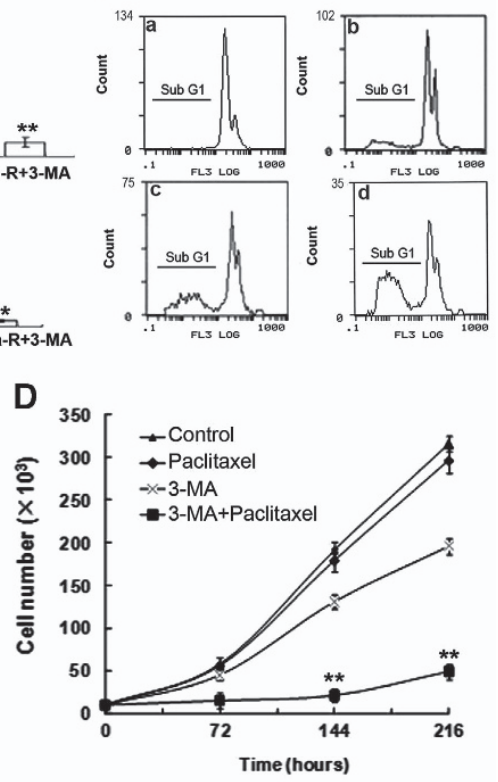

F
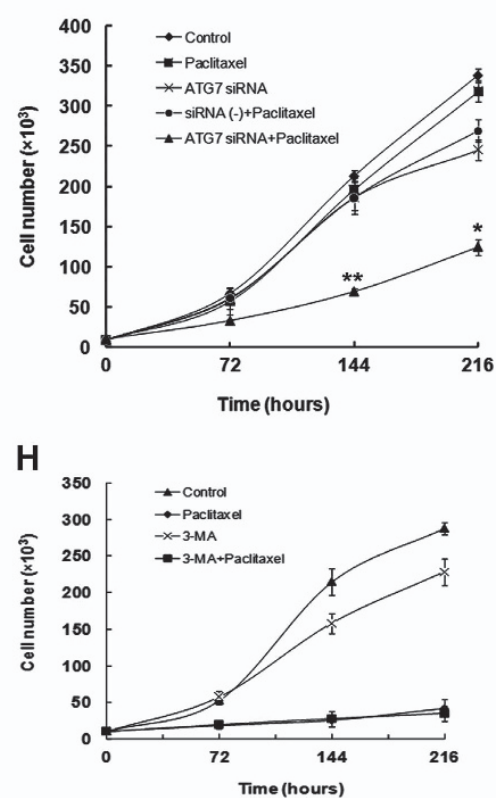

J

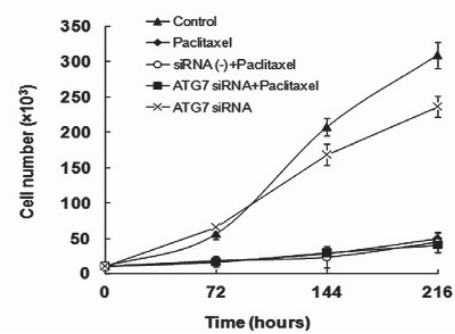


autophagy could have an important role in paclitaxel resistance of Hela-R cells.

\section{Differentially expressed proteins between HeLa and HeLa-R cells identified by 2-DE and ESI-Q-TOF} MS/MS. In order to study the molecular mechanisms underlying chemoresistance-associated autophagy, two-dimensional gel electrophoresis (2-DE) for HeLa and HeLa-R cells was repeated three times, respectively. The image assessment was conducted by using PDQuest 6.1 software and demonstrated that these 2-DE pictures were reproducible (Figure 4a). Proteins that were differentially expressed were defined as statistically significant based on two principles: (1) recurrence more than two times in the three repeated tests and (2) protein intensity changes $>2.0$-fold (Student's $t$-test, $P<0.05)$. Based on these principles above, 42 unique proteins were identified by electrospray ionization quadrupole time-of-flight (ESI-Q-TOF)-MS/MS, as shown in Table 1. According to their biological functions and subcellular localization, the classification of altered proteins was shown in Figures $4 \mathrm{~b}$ and $\mathrm{c}$.

Significant alterations were found in a group of metabolic proteins (35\% of total 42 proteins). These proteins function in diverse metabolic processes, such as glycolysis, tricarboxylic acid cycle, oxidative phosphorylation and so on. To study whether the proteomics identification of these metabolic proteins corresponded to alteration at the translational level, six proteins (PKM2, LDHA, ALDOC, TPI1, MDH1 and UQCRC1) were chosen for validation by western blot. The expression levels of these proteins agreed with the changes in 2-DE maps (Figure 4d). The data suggested that there may be the switch of cellular metabolism from tricarboxylic acid cycle to glycolysis in HeLa-R cells (Warburg effect).

Inhibition of glycolysis decreased autophagy and resensitized HeLa-R cells to paclitaxel. To investigate whether glycolysis affected autophagy and facilitated
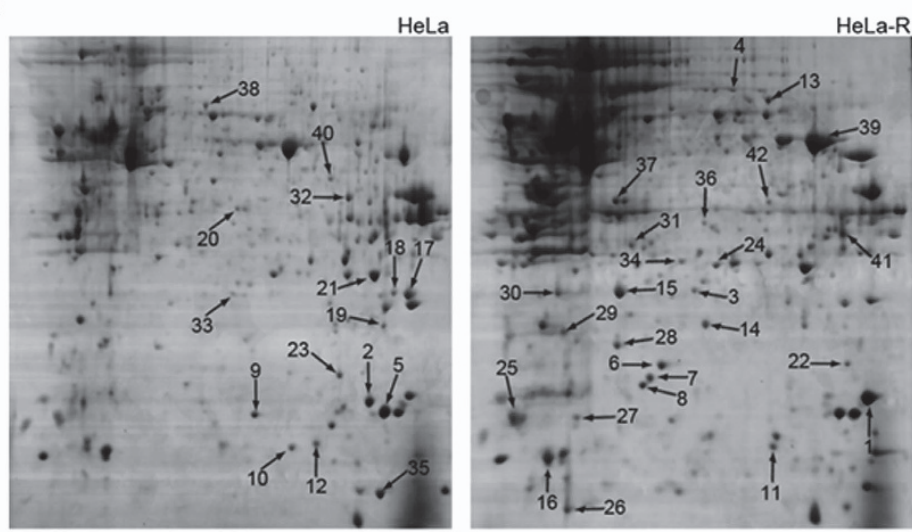

d

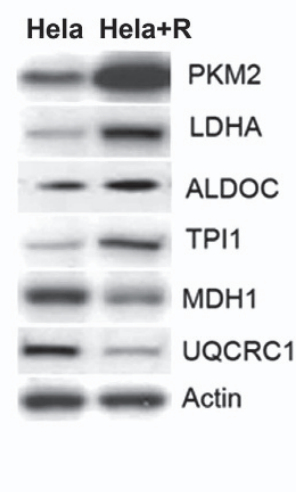

b

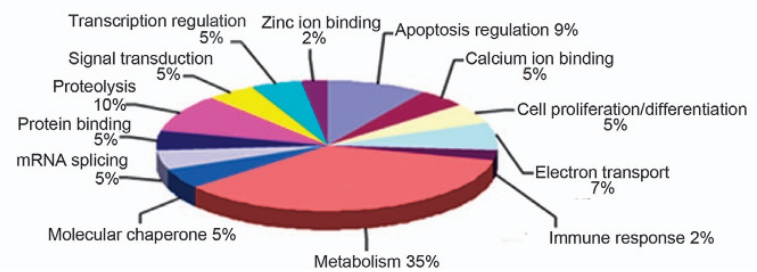

C

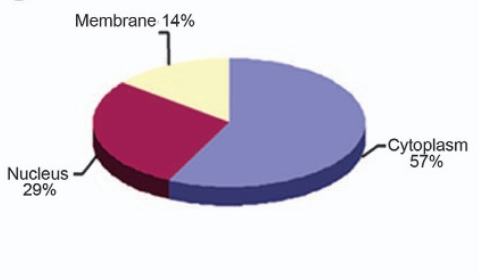

Figure 4 Proteomic analyses of differentially expressed proteins between HeLa and HeLa-R cells. (a) Representative 2-DE gel images of the HeLa and HeLa-R cells. A total of 42 spots (marked with arrow and number) were identified as differentially expressed and of these, 26 proteins were upregulated, whereas 16 proteins were downregulated in HeLa-R cells. (b) Forty-two distinct proteins were classified into 13 groups based on their biological functions: metabolism (35\%), proteolysis (10\%), apoptosis regulation (9\%), electron transport/redox regulation (7\%), molecular chaperone (5\%), signal transduction (5\%), transcription regulation (5\%), calcium ion binding $(5 \%)$ and so on. (c) The identified proteins were categorized into groups according to their subcellular locations. Among them, $57 \%$ of the proteins were located in the cytoplasm and others were located in the nucleus or membrane as indicated. (d) Western blot confirmation of six proteins (PKM2, LDHA, ALDOC, TPI1, MDH1, and UQCRC1). $\beta$-Actin was used as an equal loading control

Figure 3 Inhibition of autophagy restored HeLa-R cells sensitivity to paclitaxel. (A) Representative images of TEM (upper) and LC3 immunofluorescence staining (lower) of 3-MA (5 mM) treated HeLa-R cells. (B) Apoptosis was markedly enhanced in 3-MA plus paclitaxel-treated HeLa-R cells, compared with treatment with paclitaxel alone (2 nM), 3-MA alone (5 mM) and PBS control ( $P<0.05)$. (a) PBS control; (b) paclitaxel; (c), 3-MA; (d), paclitaxel plus 3-MA. (C and D) Cell viability and number of HeLa-R cells were significantly reduced when treated with paclitaxel plus 3-MA compared with paclitaxel alone and 3-MA alone. (E and $\mathbf{F})$ Cell viability and number of HeLa-R cells were significantly reduced in ATG7 siRNA plus paclitaxel-treated group compared with the controls. Western blot was conducted to evaluate interference efficiency. ( $\mathbf{G}$ and $\mathbf{H})$ Cell viability and number of HeLa cells were not significantly reduced in 3-MA plus paclitaxel-treated group compared with treatment with paclitaxel alone. (I and J) ATG7 siRNA could not increase paclitaxel sensitivity in parental HeLa cells. Western blot was conducted to evaluate interference efficiency. ${ }^{*} P<0.05 ;{ }^{* *} P<0.01$ 
Table 1 Identified proteins by MS/MS analysis

\begin{tabular}{|c|c|c|c|c|c|c|c|c|}
\hline $\begin{array}{l}\text { Spot } \\
\text { no. }\end{array}$ & Protein description & $\begin{array}{l}\text { Gene } \\
\text { name }\end{array}$ & Function & $\begin{array}{l}\text { Accession } \\
\text { no. }\end{array}$ & $\begin{array}{l}\text { Theoretical } \\
\text { Mr/pl }^{\mathrm{a}}\end{array}$ & Score & $\begin{array}{l}\text { No. of } \\
\text { pep }^{b}\end{array}$ & $\begin{array}{l}\text { Fold } \\
\text { change }^{c, d, e}\end{array}$ \\
\hline 1 & Peptidyl-prolyl cis-trans isomerase A & PPIA & Metabolism & P62937 & $17881 / 7.82$ & 198 & 22 & $\uparrow 2.3 \pm 0.5$ \\
\hline 2 & Ubiquitin-conjugating enzyme E2 N & UBE2N & Proteolysis & P61088 & $17184 / 6.13$ & 91 & 2 & $3.2 \pm 0.7$ \\
\hline 3 & Triosephosphate isomerase & TPl1 & Metabolism & P60174 & $26538 / 6.51$ & 634 & 17 & $\uparrow 2.9 \pm 0.4$ \\
\hline 4 & Hypoxia-inducible factor 1 -alpha & HIF1A & Metabolism & Q16665 & $92670 / 5.17$ & 145 & 12 & $\uparrow N A$ \\
\hline 5 & Nucleoside diphosphate kinase B & NME2 & Apoptosis regulation & P22392 & $17298 / 8.55$ & 45 & 1 & $\downarrow 2.0 \pm 0.2$ \\
\hline 6 & Peroxiredoxin-5 & PRDX5 & Apoptosis regulation & P30044 & $17030 / 6.73$ & 320 & 17 & $\uparrow N A$ \\
\hline 7 & $\begin{array}{l}\text { Low-molecular-weight phosphotyrosine } \\
\text { protein phosphatase }\end{array}$ & ACP1 & Metabolism & P24666 & $17911 / 6.35$ & 117 & 8 & $\uparrow N A$ \\
\hline 8 & Peroxiredoxin-2 & PRDX2 & Apoptosis regulation & P32119 & $17660 / 6.84$ & 84 & 4 & $\uparrow N A$ \\
\hline 9 & Prefoldin subunit 2 & PFDN2 & Molecular chaperone & Q9UHV9 & $16695 / 6.20$ & 161 & 6 & $\downarrow 3.7 \pm 0.9$ \\
\hline 10 & Programmed cell death protein 5 & PDCD5 & Apoptosis regulation & Q2HJH9 & $14094 / 6.21$ & 123 & 3 & $\downarrow 2.9 \pm 0.6$ \\
\hline 11 & $\begin{array}{l}\text { Cytochrome c oxidase subunit } 5 \mathrm{~A} \text {, } \\
\text { mitochondrial }\end{array}$ & COX5A & Metabolism & P20674 & $16935 / 6.30$ & 69 & 1 & $\uparrow 2.1 \pm 0.4$ \\
\hline 12 & Galectin-7 & LGALS7 & $\begin{array}{l}\text { Cell proliferation/ } \\
\text { differentiation }\end{array}$ & P47929 & $15123 / 7.03$ & 437 & 13 & $\downarrow 2.3 \pm 0.5$ \\
\hline 13 & Pyruvate kinase isozymes M1/M2 & PKM2 & Metabolism & 618 & $57805 / 7.95$ & 213 & 10 & $\uparrow 3.3 \pm 0.7$ \\
\hline 14 & Proteasome subunit beta type- 2 & PSMB2 & Proteolysis & P49721 & $22836 / 6.52$ & 436 & 36 & $\uparrow 2.5 \pm 0.3$ \\
\hline 15 & Proteasome subunit beta type- 4 & PSMB4 & Proteolysis & P28070 & $25204 / 5.47$ & 428 & 15 & $\uparrow 4.3 \pm 1.4$ \\
\hline 16 & Superoxide dismutase (Cu-Zn) & SOD1 & $\begin{array}{l}\text { Electron transport/ } \\
\text { redox regulation }\end{array}$ & P00441 & $15804 / 5.70$ & 64 & 6 & $\uparrow 2.2 \pm 0.8$ \\
\hline 17 & Splicing factor, arginine/serine-rich 7 & SFRS7 & mRNA splicing & Q16629 & $\begin{array}{l}27578 / \\
11.83\end{array}$ & 134 & 5 & $\downarrow 3.9 \pm 1.1$ \\
\hline 18 & $\begin{array}{l}\text { 3-Hydroxyacyl-CoA dehydrogenase } \\
\text { type-2 }\end{array}$ & HSD17B10 & Metabolism & Q99714 & $27134 / 7.66$ & 298 & 6 & $\downarrow 2.0 \pm 0.5$ \\
\hline 19 & Superoxide dismutase (Mn) & SOD2 & $\begin{array}{l}\text { Electron transport/ } \\
\text { redox regulation }\end{array}$ & P04179 & $24722 / 8.35$ & 52 & 3 & $\downarrow 2.1 \pm 0.3$ \\
\hline 20 & Malate dehydrogenase, cytoplasmic & $\mathrm{MDH} 1$ & Metabolism & P40925 & $36426 / 6.89$ & 391 & 9 & $\downarrow 2.3 \pm 0.6$ \\
\hline 21 & Eukaryotic translation initiation factor $4 \mathrm{H}$ & $\mathrm{EIF} 4 \mathrm{H}$ & $\begin{array}{l}\text { Transcription } \\
\text { regulation }\end{array}$ & Q15056 & $27425 / 6.67$ & 276 & 8 & $\downarrow 5.3 \pm 1.8$ \\
\hline 22 & $\begin{array}{l}\text { 28-kDa Heat- and acid-stable } \\
\text { phosphoprotein }\end{array}$ & PDAP1 & $\begin{array}{l}\text { Cell proliferation/ } \\
\text { differentiation }\end{array}$ & Q13442 & $20630 / 8.84$ & 153 & 7 & $\uparrow 2.3 \pm 1.1$ \\
\hline 23 & $\begin{array}{l}\text { Phosphatidylethanolamine-binding } \\
\text { protein }\end{array}$ & PEBP1 & Signal transduction & P30086 & $21057 / 7.01$ & 106 & 3 & $\downarrow 2.0 \pm 0.4$ \\
\hline 24 & $\begin{array}{l}26 S \text { proteasome non-ATPase regula- } \\
\text { tory subunit } 8\end{array}$ & PSMD8 & Proteolysis & P48556 & $30005 / 6.85$ & 121 & 12 & $\uparrow 2.4 \pm 0.9$ \\
\hline 25 & Myosin regulatory light polypeptide 9 & MYL9 & Calcium ion binding & P24844 & $19695 / 4.80$ & 68 & 3 & $\uparrow 2.0 \pm 0.2$ \\
\hline 26 & Ig kappa chain $\mathrm{C}$ region & IGKC & Immune response & P01834 & $11773 / 5.58$ & 378 & 11 & $\uparrow 3.4 \pm 0.7$ \\
\hline 27 & Chromobox protein homolog 3 & CBX3 & $\begin{array}{l}\text { Transcription } \\
\text { regulation }\end{array}$ & Q13185 & $20811 / 5.23$ & 256 & 8 & $\uparrow N A$ \\
\hline 28 & Heat shock protein beta- 1 & HSPB1 & Molecular chaperone & 792 & 22783 & 188 & 15 & $\uparrow 2.0 \pm 0.6$ \\
\hline 29 & Rho GDP-dissociation inhibitor 2 & ARHGDIB & Signal transduction & P52566 & $22988 / 5.1$ & 68 & 7 & $\uparrow 2.1 \pm 1.3$ \\
\hline 30 & Charged multivesicular body protein $4 \mathrm{~b}$ & CHMP4B & Protein binding & Q9H444 & $24950 / 4.76$ & 268 & 9 & $\uparrow 2.4 \pm 0.8$ \\
\hline 31 & Inorganic pyrophosphatase & PPA1 & Metabolism & Q15181 & $32660 / 5.54$ & 106 & 6 & $\uparrow 2.3 \pm 0.5$ \\
\hline 32 & $\begin{array}{l}\text { Heterogeneousnuclear ribonucleopro- } \\
\text { tein } \mathrm{H3}\end{array}$ & HNRPH3 & mRNA splicing & P31942 & $36960 / 6.37$ & 134 & 4 & $\downarrow 2.7 \pm 0.6$ \\
\hline 33 & NADH dehydrogenase flavoprotein 2 & NDUFV2 & $\begin{array}{l}\text { Electron transport/ } \\
\text { redox regulation }\end{array}$ & P19404 & $27392 / 5.22$ & 241 & 7 & $\downarrow N A$ \\
\hline 34 & LIM and SH3 domain protein 1 & LASP1 & Zinc ion binding & Q14847 & $30097 / 6.61$ & 100 & 4 & $\uparrow 2.3 \pm 0.5$ \\
\hline 35 & Tumor-suppressor candidate 2 & TUSC2 & Protein binding & O75896 & $11942 / 9.69$ & 36 & 2 & $2.0 \pm 0.7$ \\
\hline 36 & Alcohol dehydrogenase (NADP) & AKR1A1 & Metabolism & P14550 & $36892 / 6.32$ & 421 & 29 & $\uparrow 2.0 \pm 0.9$ \\
\hline 37 & Annexin A5 & ANXA5 & Calcium ion binding & P08758 & $35937 / 4.94$ & 217 & 6 & $\uparrow 3.6 \pm 1.5$ \\
\hline 38 & $\begin{array}{l}\text { Cytochrome b-c1 complex subunit } 1 \text {, } \\
\text { mitochondrial }\end{array}$ & UQCRC1 & Metabolism & P31930 & $52646 / 5.43$ & 423 & 24 & $\downarrow 2.9 \pm 1.2$ \\
\hline 39 & Creatine kinase M-type & CKM & Metabolism & P06732 & $43302 / 6.77$ & 708 & 21 & $\uparrow 5.2 \pm 1.4$ \\
\hline 40 & UDP-glucose 4-epimerase & GALE & Metabolism & Q14376 & $38656 / 6.26$ & 152 & 7 & $\downarrow 2.1 \pm 0.4$ \\
\hline 41 & L-lactate dehydrogenase A chain & LDHA & Metabolism & P00338 & $36689 / 8.46$ & 467 & 14 & $\uparrow 2.9 \pm 0.8$ \\
\hline 42 & Fructose-bisphosphate aldolase C & ALDOC & Metabolism & P09972 & $39324 / 6.46$ & 413 & 5 & $\uparrow 2.0 \pm 0.4$ \\
\hline
\end{tabular}

All protein spots identified by ESI-Q-TOF MS/MS as significantly changed in average expression level in Hela-R cells compared with parental Hela cells

${ }^{\mathrm{a}}$ Theoretical $\mathrm{Mr} / \mathrm{pl}$ : theoretical molecular weight $(\mathrm{kDa})$ and $\mathrm{pl}$ from the ExPASy database

${ }^{b}$ No. of pep: number of unique peptides identified by MS/MS sequencing

¿Upward arrows: upregulated

dDownward arrows: downregulated

eNA: the spots on one of the paired gels were too weak or nondetectable

paclitaxel resistance, we treated HeLa-R cells with 2-DG $(20 \mathrm{mM})$, an inhibitor of glycolysis, for $48 \mathrm{~h}$ in the presence or absence of paclitaxel. We found 2-DG decreased autophagy (Figure 5a). Corresponding to decreased autophagosomes, cell viability of HeLa-R cells were reduced in 2-DG plus paclitaxel-treated group compared with treatment with paclitaxel alone (2 nM), 2-DG alone $(20 \mathrm{mM})$ and PBS control (Figure 5b). In addition, apoptosis was enhanced in 2-DG plus paclitaxel-treated group, when compared with the controls (Figure 5c). 

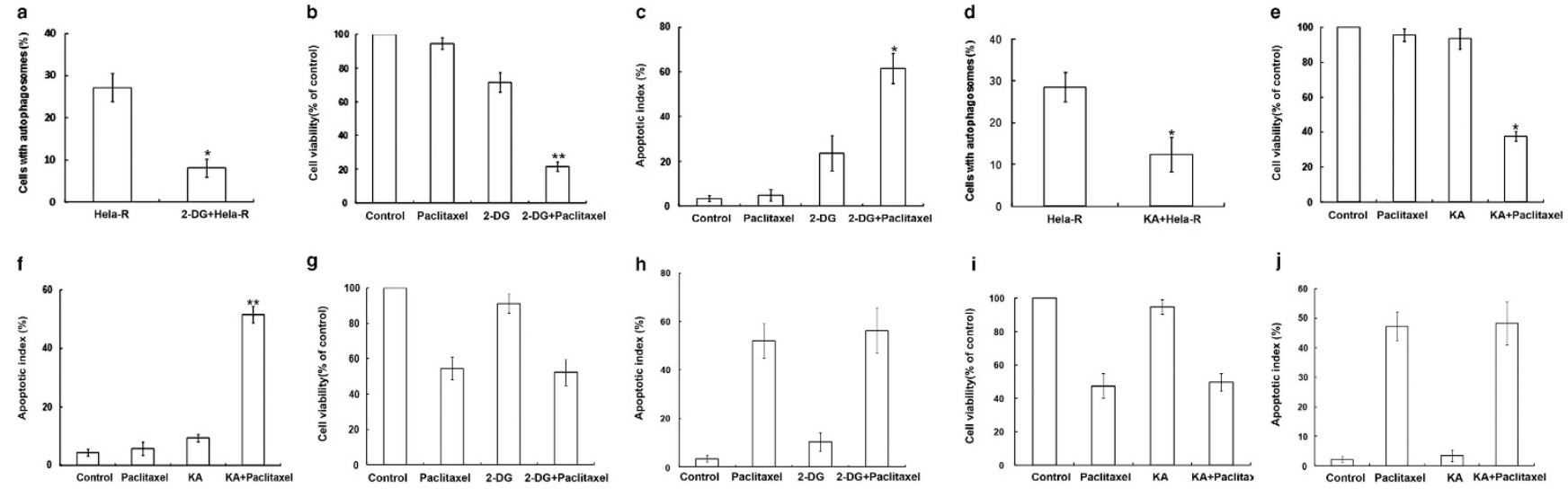

Figure 5 Inhibition of glycolysis decreased autophagy and resensitized HeLa-R cells to paclitaxel. (a) Inhibition of glycolysis by 2-DG decreased the level of autophagy in HeLa-R cells. (b) Cell viability of HeLa-R cells were obviously reduced in 2-DG plus paclitaxel-treated group compared with treatment with paclitaxel alone ( $2 \mathrm{nM}$ ), 2-DG alone $(20 \mathrm{mM})$ and PBS control. (c) Apoptosis was markedly enhanced in 2-DG plus paclitaxel-treated HeLa-R cells compared with the controls. (d) Inhibition of glycolysis by KA decreased the level of autophagy in HeLa-R cells. (e) MTT showed KA restored sensitivity of HeLa-R cells to paclitaxel. (f) Apoptosis was markedly enhanced in KA plus paclitaxel-treated HeLa-R cells compared with the controls. ( $\mathbf{g}$ and $\mathbf{h}$ ) 2-DG could not increase paclitaxel sensitivity in parental HeLa cells. (i and j) KA could not increase paclitaxel sensitivity in parental HeLa cells. Apoptotic index is reported as a percentage of sub-G1 cells versus total cells using flow cytometry. ${ }^{*} P<0.05 ;{ }^{* *} P<0.01$

In order to further confirm inhibition of glycolysis could decrease autophagy and restore HeLa-R cells sensitivity to paclitaxel, we used KA (a GAPDH inhibitor) to inhibit glycolysis. As shown in Figure 5d, KA could decrease autophagy of HeLa-R cells. Furthermore, cell viability of HeLa-R cells was significantly reduced and apoptosis was increased in KA plus paclitaxel-treated group compared with the controls (Figures $5 e$ and $f$ ). In addition, parental HeLa cells were tested for response to inhibitors of glycolysis. As shown in Figures $5 \mathrm{~g}-\mathrm{j}$, glycolysis inhibitors (2-DG or KA) could not increase paclitaxel sensitivity in parental HeLa cells. Thus, our data showed inhibition of glycolysis decreased autophagy and resensitized HeLa-R cells to paclitaxel.

Glycolysis activated HIF1- $\alpha$ and inhibition of HIF1- $\alpha$ restored HeLa-R cells sensitivity to paclitaxel. It has been reported that end products of glycolysis could activate HIF1- $\alpha$-inducible gene expression. The 2-DE data above showed that HIF1- $\alpha$ (Figure 4a, Table 1 Spot NO. 4) was upregulated. In order to validate the expression of HIF1- $\alpha$ in HeLa-R cells, western blot was conducted. As shown in Figure 6a, HIF1- $\alpha$ was obviously upregulated in HeLa-R cells. Moreover, inhibition of glycolysis by 2-DG could decrease the expression of HIF1- $\alpha$ in HeLa-R cells (Figure $6 \mathrm{~b}$ ). In addition, we used HIF1- $\alpha$-specific siRNA to transfect HeLa-R cells to inhibit the expression of HIF1- $\alpha$, then examined the expression of a critical molecule in autophagy pathway-Beclin 1 by western blot. As a result, Beclin 1 was downregulated significantly after inhibition of HIF1- $\alpha$ (Figure 6c). Moreover, data from electron microscopy and LC3 immunofluorescence also showed similar results (Figures $6 \mathrm{~d}$ and e). So HIF1- $\alpha$ is involved in the regulation of chemoresistance-associated autophagy in HeLa-R cells. MTT assay revealed that HIF1- $\alpha$ siRNA plus paclitaxeltreated group could increase paclitaxel sensitivity compared with the controls (Figure 6f). Flow cytometry showed the significant increase of apoptotic cells in the HIF1- $\alpha$ siRNA plus paclitaxel group compared with the controls (Figure $6 \mathrm{~g}$ ). These findings showed that glycolysis activated HIF $1-\alpha$ and downregulation of HIF1- $\alpha$ could resensitize HeLa-R cells to paclitaxel.

Increased autophagy and upregulation of glycolytic molecules in clinical tissues from patients who were resistant to paclitaxel chemotherapy. In order to study whether these results above were consistent with clinical samples, fresh tumor tissues were obtain from 6 cervical cancer patients who were resistant to paclitaxel-based chemotherapy and 15 cervical cancer patients who were clinically responsive to paclitaxel-based chemotherapy. This study was approved by the Institutional Ethics Committee of Sichuan University and informed consents were obtained from all patients before analysis. TEM showed autophagy was activated in paclitaxel-resistant tumor tissues when compared with paclitaxel-sensitive tumor tissues $(P<0.05)$ (Supplementary Figure 1sA). Real-time quantitative RT-PCR was conducted to examine the expression level of PKM2, LDHA, ALDOC and TPI1. As shown in Supplementary Figure 1sB, the mRNA expression level of PKM2, LDHA, ALDOC and TPI1 in paclitaxel-resistant cervical cancer was significantly higher compared with paclitaxel-sensitive tumor tissues $(P<0.05)$. The data were consistent with our results from HeLa-R cell lines. Thus, Warburg effect activated HIF1$\alpha$-mediated signaling-induced autophagic pathway may have an important role in paclitaxel chemoresistance.

\section{Discussion}

Paclitaxel is an extensively used anticancer drug for the treatment of many types of cancers, including lung cancer, breast cancer, cervical cancer and so on. Paclitaxel resistance may contribute to the consecutive recurrence and metastasis of cancer, finally causing death. ${ }^{24,25}$ Although many studies have been conducted about the paclitaxel resistance, the specific mechanisms of action involved are still poorly understood.

In this report, paclitaxel-resistant cervical cancer cells (HeLa-R cells) were induced by a stepwise selection of 
a

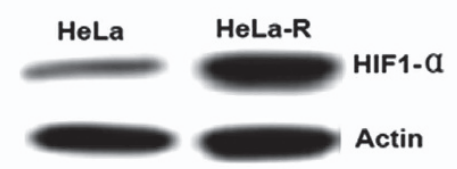

d

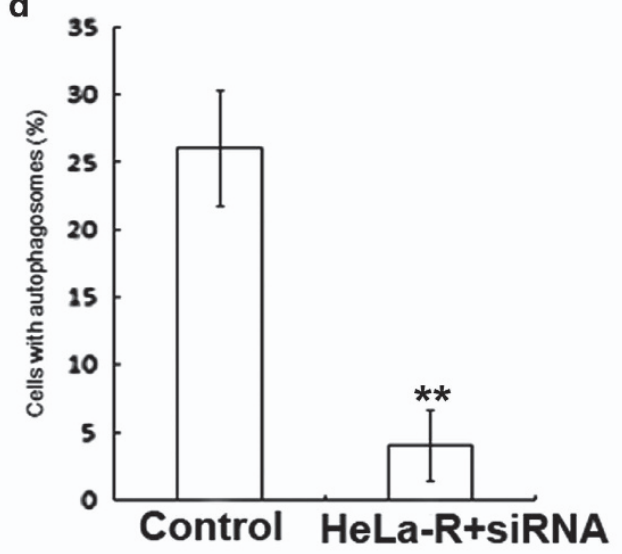

b

Hela-R 2-DG+Hela-R

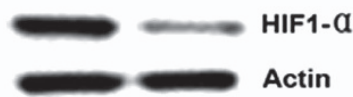

e

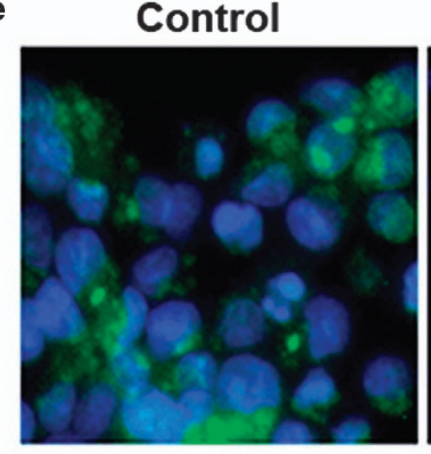

C

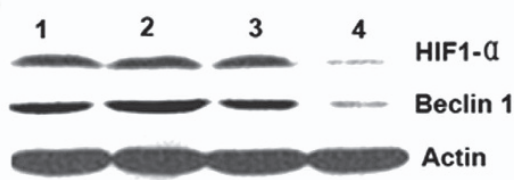

HeLa-R+siRNA

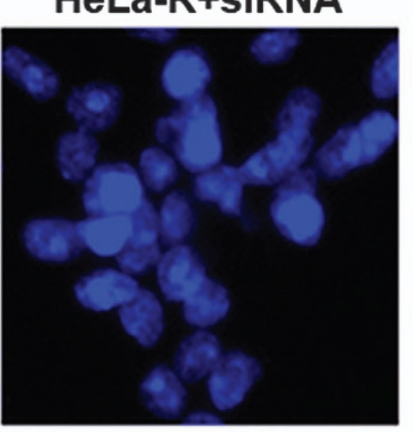

f

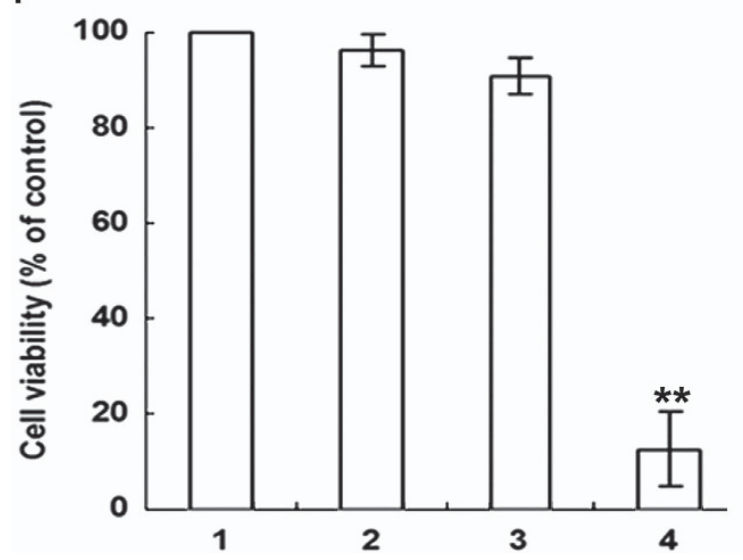

g

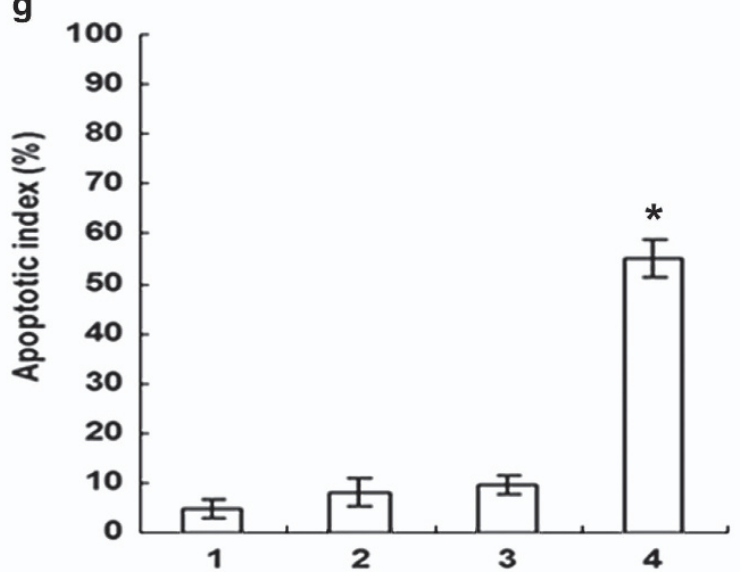

Figure 6 Glycolysis activated HIF1- $\alpha$ and inhibition of HIF1- $\alpha$ restored HeLa-R cells sensitivity to paclitaxel. (a) Western blot showed HIF1- $\alpha$ was obviously upregulated in HeLa-R cells. (b) Inhibition of glycolysis by 2-DG could decrease the expression of HIF1- $\alpha$ in HeLa-R cells. (c) HIF1- $\alpha$ siRNA was used to transfect HeLa-R cells, then examined the expression of Beclin 1 by western blot. As a result, Beclin 1 was downregulated significantly after inhibition of HIF1- $\alpha$. (1) Untreated HeLa-R cells; (2) liposometreated HeLa-R cells; (3) negative control-treated HeLa-R cells; (4) HIF1- $\alpha$ siRNA-treated HeLa-R cells. (d) Data of TEM of HIF1- $\alpha$ siRNA-treated HeLa-R cells. (e) Representative images of LC3 immunofluorescence staining of HIF1- $\alpha$ siRNA-treated HeLa-R cells. (f) MTT assay revealed that HIF1- $\alpha$ siRNA plus paclitaxel-treated group could increase paclitaxel sensitivity compared with the controls. (1) Untreated HeLa-R cells; (2) paclitaxel-treated HeLa-R cells; (3) negative control plus paclitaxeltreated HeLa-R cells; (4) HIF1- $\alpha$ siRNA plus paclitaxel-treated HeLa-R cells. (g) Flow cytometry showed the significant increase of apoptotic cells in the HIF1- $\alpha$ siRNA plus paclitaxel group compared with the controls. (1) Untreated HeLa-R cells; (2) paclitaxel-treated HeLa-R cells; (3) negative control plus paclitaxel-treated HeLa-R cells; (4) HIF1- $\alpha$ siRNA plus paclitaxel-treated HeLa-R cells. Apoptotic index is reported as a percentage of sub-G1 cells versus total cells using flow cytometry. ${ }^{*} P<0.05 ;{ }^{* *} P<0.01$

various doses of paclitaxel. Our data showed that autophagy was activated in HeLa-R cells, which was confirmed by formation of autophagosomes, appearance of punctate patterns of LC3 and activation of autophagy genes, including LC3-II, Beclin 1, the Atg12-Atg5 conjugate and Atg7, which are necessary for autophagosome formation. Furthermore, inhibition of autophagy by 3-MA or ATG7 siRNA restored HeLa-R cells sensitivity to paclitaxel. However, 3-MA or ATG7 siRNA could not increase paclitaxel sensitivity in parental HeLa cells. Thus, autophagy, a prosurvival way, could facilitate the development of acquired resistance of paclitaxel. In order to study the underlying mechanism of chemoresistance-associated autophagy, 2-DE combined with
ESI-Q-TOF MS/MS identification was utilized to profile differentially expressed proteins between HeLa and HeLa-R cells. In our proteomic study, a series of enzymes involved in energy metabolism were identified with obviously changed expression levels, which may display the switch of cellular metabolism from tricarboxylic acid cycle to glycolysis (known as Warburg effect). Furthermore, our findings showed that inhibition of glycolysis decreased autophagy and resensitized HeLa-R cells to paclitaxel. As it was reported that Warburg effect could promote HIF1- $\alpha$ protein stability and activate HIF1- $\alpha$-inducible gene expression, ${ }^{26,27}$ it was of particular interest to examine whether expression of HIF1- $\alpha$ was altered in HeLa-R cells. We found HIF1- $\alpha$ was obviously upregulated 
in HeLa-R cells. Moreover, inhibition of glycolysis by 2-DG could decrease the expression of HIF1- $\alpha$ in HeLa-R cells. HIF1- $\alpha$-specific siRNA could decrease autophagy and resensitize HeLa-R cells to paclitaxel. Finally, increased autophagy and upregulation of glycolytic molecules were found in clinical tissues from patients who were resistant to paclitaxel chemotherapy when compared with paclitaxel-sensitive tumor tissues. The findings need to be further confirmed by more clinical specimens in our next experiments. Taken together, Warburg effect activated HIF1- $\alpha$-mediated signaling-induced autophagic pathway may have an important role in paclitaxel chemoresistance.

Tumor cells are different from normal somatic cells in their metabolic mode, with normal somatic cells depending mainly on mitochondrial oxidative phosphorylation, making use of glucose and oxygen to generate energy. In tumor cells, energy production mainly depends on glycolysis even though oxygen is rich. ${ }^{28-30}$ Although the molecular mechanisms of action underlying the Warburg effect remain obscure, it has been well accepted that increased glycolysis in tumor cells is a very key process to sustain malignant phenotypes. ${ }^{31}$ It has been shown that targeting the key enzymes of glycolysis can sensitize cancer cells to chemotherapy. ${ }^{24,32,33}$ For example, $\mathrm{LDH}-\mathrm{A}$ is one of the primary isoforms of LDH, which controls the transition of pyruvate to lactate of glycolysis and has a vital role in sustaining energy metabolism of tumor cell. If its action is repressed, the energy-producing task will be transferred to cellular mitochondria that can contribute to increased oxidative stress and promote apoptosis of mitochondrial pathway. Targeting LDH-A by siRNA or oxamate (a competitive inhibitor of LDH-A) could resensitize chemoresistant cells to paclitaxel. ${ }^{24}$ PKM2, a very vital enzyme that can regulate aerobic glycolysis, has an important part in cancer metabolism and proliferation. The combination of shRNA targeting PKM2 and cisplatin or docetaxel suppressed lung carcinoma growth and induced more apoptosis of tumor cells both in vitro and in vivo. ${ }^{32,33} \mathrm{~A}$ finding by proteomic analysis in our study is that the key proteins of tricarboxylic acid cycle (such as MDH1 and UQCRC1) were downregulated, while the key proteins of glycolysis (such as PKM2, LDHA, ALDOC and TPI1) were upregulated, which may display the switch of cellular metabolism from tricarboxylic acid cycle to glycolysis.

HIF1 is a heterodimer composed of two subunits, HIF1- $\alpha$ and HIF1- $\beta$, both of which are constitutively expressed in mammalian cells. ${ }^{34}$ The regulation of the HIF1 complex is mainly dependent on the degradation of the HIF1- $\alpha$ subunit. HIF1- $\alpha$ activation is highly associated with tumor cell growth, metastasis and poor clinical prognosis. ${ }^{35,36}$ It has been reported that end products of glycolytic metabolism can promote HIF1- $\alpha$ protein stability and activate HIF1- $\alpha$-inducible gene expression. ${ }^{27}$ Moreover, glycolysis can contribute to induction of HIF1- $\alpha$ in a hypoxia-independent way by several endocrine agents and environmental toxins. ${ }^{37,38}$ Our findings agreed with what was reported before. HIF $1-\alpha$ was obviously upregulated in HeLa-R cells and HIF1- $\alpha$-specific siRNA could resensitize HeLa-R cells to paclitaxel.

In conclusion, a possible novel Warburg effect activated HIF1- $\alpha$-mediated signaling-induced autophagic pathway is proposed, which may provide new insight into paclitaxel chemoresistance.

\section{Materials and Methods}

Cell culture and reagents. HeLa (from American Type Culture Collection, Manassas, VA, USA) and HeLa-R cells were cultured at $37^{\circ} \mathrm{C}$ in DMEM in a humid incubator with $5 \% \mathrm{CO}_{2}$.

Reagents used in this study were: 3-MA (M9281) was purchased from SigmaAldrich (St. Louis, MO, USA). Lipofectamine 2000 reagent was purchased from Invitrogen, Karlsruhe, Germany. 2-DG (D8375) was obtained from Sigma, St. Louis, MO, USA. KA (57710-57-3) was obtained from TMS Co. Ltd (Suwon, South Korea).

Antibodies used in this study were: P62 antibody (Abcam, Cambridge, UK; ab56416), Beclin 1 (Santa Cruz Biotechnology, Santa Cruz, CA, USA; sc-11427), LC3 (Abcam, ab58610), Atg12-Atg5 (Abcam, ab78073), Atg7 (Abcam, ab53255), PKM2 (Abcam, ab58610), LDHA (Abcam, ab47010), ALDOC (Abcam, ab71294), TPI1 (Abcam, ab96696), MDH1 (Abcam, ab76616), UQCRC1 (Abcam, ab96333), HIF-1 $\alpha$ (Abcam, ab16066), horseradish peroxidase (HRP)-conjugated anti-rabbit secondary antibody (Santa Cruz Biotechnology, sc-2004), HRP-conjugated antimouse secondary antibody (Santa Cruz Biotechnology, sc-2005).

Establishment of HeLa-R. HeLa cells were seeded in six-well plates and were allowed to reach about $80 \%$ confluency in fresh medium before treating with paclitaxel. The dose of paclitaxel begun with $0.04 \mathrm{nM}$ (about 1/50 IC50, IC50: $1.87 \mathrm{nM}$ in HeLa cells), and it was increased by a dose gradient that was $25-50 \%$ of the previous dose. The next dose was given until the cells were stable in proliferation without significant death.

Cell viability and proliferation assays. For the proliferation assay, cells were seeded at $5 \times 10^{3}$ cells per well in 96-well plates. Afterward, medium containing agents were added to each well and cells were further cultured at $37^{\circ} \mathrm{C}$ for the indicated times. Cell viability was examined by MTT test and neutral red uptake cytotoxicity assay. The results were from three independent experiments of each group.

Cells were trypsinized and replated in 24-well plates at a density of 10000 cells per well. Cells were incubated for $24 \mathrm{~h}$ to allow for attachment, after which a zero time point was determined. Afterward, medium containing agents were added to each well and cells were counted at days 0, 3, 6 and 9 with a Coulter Counter (Coulter Electronics, Inc., Hialeah, FL, USA). All assays were performed at least three times in duplicate.

Flow cytometry. Flow cytometric analysis was performed to identify sub-G1 cells/apoptotic cells and to measure the percentage of sub-G1 cells after propidium iodide (PI) staining in hypotonic buffer as described. ${ }^{39,40}$ Briefly, cells were suspended in $1 \mathrm{ml}$ hypotonic fluorochrome PI solution $(50 \mu \mathrm{g} / \mathrm{ml} \mathrm{PI}$ in $0.1 \%$ sodium citrate plus $0.1 \%$ Triton $\mathrm{X}-100$ ) containing $0.5 \mathrm{mg} / \mathrm{ml}$ RNase $\mathrm{A}$, and the cells were analyzed by the use of a flow cytometer (ESP Elite, Beckman Coulter, Fullerton, CA, USA). Apoptotic cells appeared in the cell cycle distribution as cells with DNA content of less than that of G1 cells.

Electron microscopy. Cells were harvested, pelleted and fixed in paraformaldehyde, $0.1 \%$ glutaraldehyde in $0.1 \mathrm{M}$ sodium cacodylate for $2 \mathrm{~h}$, postfixed with $1 \% \mathrm{OsO}_{4}$ for $1.5 \mathrm{~h}$, washed and finally stained for $1 \mathrm{~h}$ in $3 \%$ aqueous uranyl acetate. The samples were then rinsed with water again, dehydrated with graded alcohol (50\%, 75\% and $95-100 \%$ alcohol) and embedded in Epon-Araldite resin (Canemco, St. Laurent, QC, Canada; 034). Ultrathin sections were cut on a Reichert Ultramicrotome, counterstained with $0.3 \%$ lead citrate and examined on a Philips EM420 transmission electron microscope (Philips, Eindhoven, The Netherlands). Values for the area occupied by autophagic vacuoles and the cytoplasm were obtained with Image Pro Plus version 3 (Media Cybernetics, Silver Spring, MA, USA) and used for the calculation of the cytoplasmic area occupied by the autophagic vacuoles.

Immunofluorescence of LC3. Treated cells were washed with PBS and then fixed with paraformaldehyde $(4 \% \mathrm{w} / \mathrm{v})$. After rinsing in PBS, the cells were blocked with $0.1 \%$ Triton $\mathrm{X}-100$ containing $1 \%$ bovine serum albumin in PBS for $1 \mathrm{~h}$. This was followed by incubation in LC3 antibody (Abcam, ab58610) for $24 \mathrm{~h}$ at $4^{\circ} \mathrm{C}$ in a humidified chamber. After three washes in PBS, the cells were incubated in secondary antibody conjugated to HRP for $2 \mathrm{~h}$ at room temperature. Finally, cells were rinsed in PBS, coverslipped and examined with fluorescence microscopy.

siRNA preparation and transfection. Atg7 and HIF1- $\alpha$ knockdowns were accomplished by transfecting cells with siRNA. Atg7 and control siRNA were 
synthesized by RiboBio (Guangzhou, China). HIF1- $\alpha$ and control siRNA were synthesized by Santa Cruz Biotechnology. The siRNA sequences against Atg7 or HIF1- $\alpha$ were previously described. ${ }^{41,42}$ Cells were transfected with $1 \mu \mathrm{g}$ siRNA using $2.5 \mu \mathrm{g}$ Lipofectamine 2000 reagent (Invitrogen). Scrambled siRNA, which consists of a scrambled sequence that will not lead to specific degradation of any known cellular mRNA, was used as negative control.

Western blot. Proteins were extracted in RIPA buffer $(50 \mathrm{mM}$ Tris-base, $1.0 \mathrm{mM}$ EDTA, $150 \mathrm{mM} \mathrm{NaCl}, 0.1 \%$ SDS, $1 \%$ Triton X-100, $1 \%$ sodium deoxycholate, $1 \mathrm{mM}$ PMSF) and quantified by the DC protein assay kit (Bio-Rad, Berkeley, CA, USA). Samples were separated by $12 \%$ SDS-PAGE and transferred to PVDF membranes (Amersham Biosciences, Piscataway, NJ, USA). After blocking with 5\% non-fat milk in Tris-buffered saline, $0.1 \%$ Tween 20 for $1 \mathrm{~h}$, the membranes were incubated overnight at $4{ }^{\circ} \mathrm{C}$ with respective primary antibodies. After that, the blots were incubated with secondary antibody conjugated to HRP for $2 \mathrm{~h}$ at room temperature. Target proteins were detected by enhanced chemiluminescence reagents (Amersham Pharmacia Biotech, Piscataway, NJ, USA).

2-DE and image analysis. Cells were lysed in lysis buffer $(7 \mathrm{M}$ urea, $2 \mathrm{M}$ thiourea, 4\% CHAPS, $100 \mathrm{mM}$ DTT, 0.2\% pH 3-10 ampholyte, Bio-Rad) containing protease inhibitor cocktail 8340 (Sigma). Protein samples $(2 \mathrm{mg}$ ) were applied to IPG strip (17 cm, pH3-10 NL, Bio-Rad) using a passive rehydration method. After 12-16 h of rehydration, the strips were transferred to an IEF Cell (Bio-Rad). IEF was performed as follows: $250 \mathrm{~V}$ for $30 \mathrm{~min}$, linear; $1000 \mathrm{~V}$ for $1 \mathrm{~h}$, rapid; linear ramping to $10000 \mathrm{~V}$ for $5 \mathrm{~h}$ and finally $10000 \mathrm{~V}$ for $4 \mathrm{~h}$. The second dimension was performed using $12 \%$ SDS-PAGE at $30 \mathrm{~mA}$ constant current per gel after equilibration. The gels were stained using CBB R-250 (Merck, Darmstadt, Germany) and scanned with a Bio-Rad GS-800 scanner. Three independent runs were made to ensure the accuracy of analyses. The maps were analyzed by PDQuest software Version 6.1 (Bio-Rad). The quantity of each spot in a gel was normalized as a percentage of the total quantity of all spots in that gel and evaluated in terms of OD. For statistical analysis, paired $t$-test was performed to compare data from the three repeated experiments. Only spots that showed consistent and significant differences ( \pm over twofold, $P<0.05)$ were selected for analysis with MS.

Mass spectrometry analysis. Gel bands were cut out and prepared for mass spectrometry analysis with trypsin digestion. Peptides were analyzed using a Q-TOF mass spectrometer (Micromass, Manchester, UK) fitted with an ESI source (Waters, Manchester, UK).

Real-time RT-PCR. mRNA was isolated from frozen tumor tissue using RNeasy total RNA kits (Qiagen, Hilden, Germany). RNA concentration was evaluated by photometric measurement at $260 / 280 \mathrm{~nm}$. One microgram RNA was used for cDNA synthesis using the QuantiTect Reverse Transcription Kit (Qiagen). PCR reactions were performed by using the Platinum SYBR Green qPCR SuperMix-UDG (Invitrogen) in the 7300 real-time PCR system (Applied Biosystems, Darmstadt, Germany). The paired forward and reverse primers are as follows: PKM2 (forward): 5'-ATTATTTGAGGAACTCCGCCGCCT-3', and (reverse): 5'-ATTCCGGGTCACAGCAATGATGG-3'; LDHA (forward): 5'-CTCCT GTGCAAAATGGCAAC- $3^{\prime}$, and (reverse): $5^{\prime}$-CCTAGAGCTCACTAGTCACAG-3'; ALDOC (forward) $5^{\prime}$-GCCAAATTGGGGTGGAAAACA-3', and (reverse) $5^{\prime}$-TTCAC ACGGTCATCAGCACTG-3'; TPI1 (forward): 5'- CGGGATCCAGCGCCTCGGCT CCAGCG-3', and (reverse): 5'-GGGGTACCAGTTGTTTGGCATTGATGATGTC CACG- $3^{\prime}$. The experiment was repeated three times.

Statistical analyses. Statistical comparisons of mean values were performed using an analysis of variance. Statistical significance was defined as ${ }^{\star} P<0.05 ;{ }^{\star \star} P<0.01$.

\section{Conflict of Interest}

The authors declare no conflict of interest.

Acknowledgements. This work was supported by the grants from National Natural Sciences Foundation of China (81301794), Postdoctoral 52nd Foundation of China (2012M521701), Technology innovation seedling cultivation project of Sichuan province (0030405301429) and National science and technology major projects (2009ZX09503-020).
1. Jemal A, Siegel R, Xu J, Ward E. Cancer statistics, 2010. Cancer J Clin 2010; 60: 277-300.

2. Pectasides D, Kamposioras K, Papaxoinis G, Pectasides E. Chemotherapy for recurrent cervical cancer. Cancer Treatment Rev 2008; 34: 603-613.

3. Frankel A, Buckman R, Kerbel RS. Abrogation of taxol-induced G2-M arrest and apoptosis in human ovarian cancer cells grown as multicellular tumor spheroids. Cancer Res 1997; 57: 2388-2393

4. Gottesman MM, Pastan I. Biochemistry of multidrug resistance mediated by the multidrug transporter. Annu Rev Biochem 1993; 62: 385-427.

5. Gottesman MM, Fojo T, Bates SE. Multidrug resistance in cancer: role of ATP-dependent transporters. Nat Rev Cancer 2002; 2: 48-58.

6. Szakacs G, Paterson JK, Ludwig JA, Booth-Genthe C, Gottesman MM. Targeting multidrug resistance in cancer. Nat Rev Drug Discov 2006; 5: 219-234.

7. Goncalves A, Braguer D, Kamath K, Martello L, Briand C, Horwitz S et al. Resistance to Taxol in lung cancer cells associated with increased microtubule dynamics. Proc Natl Acad Sci USA 2001; 98: 11737-11742.

8. Kavallaris M, Kuo DY, Burkhart CA, Regl DL, Norris MD, Haber M et al. Taxol-resistant epithelial ovarian tumors are associated with altered expression of specific beta-tubulin isotypes. J Clin Invest 1997; 100: 1282-1293.

9. Tan M, Jing T, Lan KH, Neal CL, Li P, Lee $S$ et al. Phosphorylation on tyrosine-15 of p34(Cdc2) by ErbB2 inhibits p34(Cdc2) activation and is involved in resistance to taxolinduced apoptosis. Mol Cell 2002; 9: 993-1004.

10. Lu J, Tan M, Huang WC, Li P, Guo H, Tseng LM et al. Mitotic deregulation by survivin in ErbB2-overexpressing breast cancer cells contributes to taxol resistance. Clin Cancer Res 2009; 15: 1326-1334.

11. Ajabnoor GM, Crook T, Coley HM. Paclitaxel resistance is associated with switch from apoptotic to autophagic cell death in MCF-7 breast cancer cells. Cell death dis 2012; 3 : e260.

12. Mizushima N, Levine B, Cuervo AM, Klionsky DJ. Autophagy fights disease through cellular self-digestion. Nature 2008; 451: 1069-1075.

13. Levine B, Klionsky DJ. Development by self-digestion: molecular mechanisms and biological functions of autophagy. Dev cell 2004; 6: 463-477.

14. Pyo JO, Jang MH, Kwon YK, Lee HJ, Jun JI, Woo HN et al. Essential roles of Atg5 and FADD in autophagic cell death: dissection of autophagic cell death into vacuole formation and cell death. J Biological Chemistry 2005; 280: 20722-20729.

15. Pattingre S, Tassa A, Qu X, Garuti R, Liang XH, Mizushima N et al. Bcl-2 antiapoptotic proteins inhibit Beclin 1-dependent autophagy. Cell 2005; 122: 927-939.

16. Melendez A, Talloczy Z, Seaman M, Eskelinen EL, Hall DH, Levine B. Autophagy genes are essential for dauer development and life-span extension in C. elegans. Science 2003; 301: 1387-1391.

17. Yu L, Alva A, Su H, Dutt P, Freundt E, Welsh $S$ et al. Regulation of an ATG7-beclin 1 program of autophagic cell death by caspase-8. Science 2004; 304: 1500-1502.

18. Petiot A, Ogier-Denis E, Blommaart EF, Meijer AJ, Codogno P. Distinct classes of phosphatidylinositol 3 '-kinases are involved in signaling pathways that control macroautophagy in HT-29 cells. J Biol Chem 2000; 275: 992-998.

19. Hashimoto D, Ohmuraya M, Hirota M, Yamamoto A, Suyama K, Ida S et al. Involvement of autophagy in trypsinogen activation within the pancreatic acinar cells. J Cell Bio/ 2008; 181: 1065-1072.

20. Kondo $\mathrm{Y}$, Kanzawa $\mathrm{T}$, Sawaya R, Kondo $\mathrm{S}$. The role of autophagy in cancer development and response to therapy. Nat Rev Cancer 2005; 5: 726-734.

21. Li J, Hou N, Faried A, Tsutsumi S, Kuwano H. Inhibition of autophagy augments 5 -fluorouracil chemotherapy in human colon cancer in vitro and in vivo model. Eur J Cancer 2010; 46: 1900-1909.

22. Apel A, Herr I, Schwarz H, Rodemann HP, Mayer A. Blocked autophagy sensitizes resistant carcinoma cells to radiation therapy. Cancer Res 2008; 68: 1485-1494.

23. Komatsu M, Waguri S, Ueno T, Iwata J, Murata S, Tanida I et al. Impairment of starvation-induced and constitutive autophagy in Atg7-deficient mice. J Cell Biol 2005; 169: 425-434.

24. Zhou M, Zhao Y, Ding Y, Liu H, Liu Z, Fodstad O et al. Warburg effect in chemosensitivity: targeting lactate dehydrogenase-A re-sensitizes taxol-resistant cancer cells to taxol. Mol Cancer 2010; 9 : 33.

25. Semenza GL, Jiang BH, Leung SW, Passantino R, Concordet JP, Maire P et al. Hypoxia response elements in the aldolase $A$, enolase 1 , and lactate dehydrogenase $A$ gene promoters contain essential binding sites for hypoxia-inducible factor 1. J Biol Chem 1996; 271: 32529-32537.

26. Lu H, Forbes RA, Verma A. Hypoxia-inducible factor 1 activation by aerobic glycolysis implicates the Warburg effect in carcinogenesis. J Biol Chem 2002; 277: 23111-23115.

27. Christofk HR, Vander Heiden MG, Wu N, Asara JM, Cantley LC. Pyruvate kinase M2 is a phosphotyrosine-binding protein. Nature 2008; 452: 181-186.

28. Annibaldi A, Widmann C. Glucose metabolism in cancer cells. Curr Opin Clin Nutr Metab Care 2010; 13: 466-470.

29. Vander Heiden MG, Cantley LC, Thompson CB. Understanding the Warburg effect: the metabolic requirements of cell proliferation. Science 2009; 324: 1029-1033.

30. Bensinger SJ, Christofk HR. New aspects of the Warburg effect in cancer cell biology. Sem Cell Dev Biol 2012; 23: 352-361.

31. Gillies RJ, Robey I, Gatenby RA. Causes and consequences of increased glucose metabolism of cancers. J Nuclear Med 2008; 49(Suppl 2): 24S-42S. 
32. Shi HS, Li D, Zhang J, Wang YS, Yang L, Zhang HL et al. Silencing of pkm2 increases the efficacy of docetaxel in human lung cancer xenografts in mice. Cancer Sci 2010; 101: 1447-1453.

33. Guo W, Zhang Y, Chen T, Wang Y, Xue J, Xiao W et al. Efficacy of RNAi targeting of pyruvate kinase M2 combined with cisplatin in a lung cancer model. J Cancer Res Clin Oncol 2011; 137: 65-72.

34. Wang GL, Semenza GL. Purification and characterization of hypoxia-inducible factor 1 . J Biol Chem 1995; 270: 1230-1237.

35. Akakura N, Kobayashi M, Horiuchi I, Suzuki A, Wang J, Chen J et al. Constitutive expression of hypoxia-inducible factor-1alpha renders pancreatic cancer cells resistant to apoptosis induced by hypoxia and nutrient deprivation. Cancer Res 2001; 61: 6548-6554.

36. Kung AL, Wang S, Klco JM, Kaelin WG, Livingston DM. Suppression of tumor growth through disruption of hypoxia-inducible transcription. Nat Med 2000; 6: 1335-1340.

37. Zhong H, Chiles K, Feldser D, Laughner E, Hanrahan C, Georgescu MM et al. Modulation of hypoxia-inducible factor 1alpha expression by the epidermal growth factor/ phosphatidylinositol 3-kinase/PTEN/AKT/FRAP pathway in human prostate cancer cells: implications for tumor angiogenesis and therapeutics. Cancer Res 2000; 60: 1541-1545.

38. Richard DE, Berra E, Pouyssegur J. Nonhypoxic pathway mediates the induction of hypoxia-inducible factor 1alpha in vascular smooth muscle cells. J Biol Chem 2000; 275 : 26765-26771.

39. Qu X, Qing L. Abrin induces HeLa cell apoptosis by cytochrome c release and caspase activation. J Biochem Mol Biol 2004; 37: 445-453.
40. Li Q, Wei YQ, Wen YJ, Zhao X, Tian L, Yang L et al. Induction of apoptosis and tumor regression by vesicular stomatitis virus in the presence of gemcitabine in lung cancer. Int J Cancer 2004; 112: 143-149.

41. Kessler J, Hahnel A, Wichmann H, Rot S, Kappler M, Bache M et al. HIF-1alpha inhibition by siRNA or chetomin in human malignant glioma cells: effects on hypoxic radioresistance and monitoring via CA9 expression. BMC Cancer 2010; 10: 605.

42. Lavieu G, Scarlatti F, Sala G, Carpentier S, Levade T, Ghidoni R et al. Regulation of autophagy by sphingosine kinase 1 and its role in cell survival during nutrient starvation. J Biol Chem 2006; 281: 8518-8527.

(c) (i) $\odot$ Cell Death and Disease is an open-access journal published by Nature Publishing Group. This work is licensed under a Creative Commons Attribution-NonCommercialNoDerivs 3.0 Unported License. The images or other third party material in this article are included in the article's Creative Commons license, unless indicated otherwise in the credit line; if the material is not included under the Creative Commons license, users will need to obtain permission from the license holder to reproduce the material. To view a copy of this license, visit http://creativecommons.org/ licenses/by-nc-nd/3.0/

Supplementary Information accompanies this paper on Cell Death and Disease website (http://www.nature.com/cddis) 